УДК

\title{
ВЫБОР ГИПЕРХАОТИЧЕСКИХ ПОСЛЕДОВАТЕЛЬНОСТЕЙ РАСШИРЕННОГО СПЕКТРА И ИХ ПРИМЕНЕНИЕ В СИСТЕМЕ DS-CDМА*
}

\author{
ЛИ Ш., ЛИАН Х., ЖАО Я., ВУ Ж. \\ Харбинский политехнический университет, \\ Китай, Харбин, Хэйлунизян
}

\begin{abstract}
Аннотация. Предложен новый алгоритм для выбора гиперхаотических последовательностей расширенного спектра. Двоичные гиперхаотические последовательности расширенного спектра формируются с помощью клеточной нейронной сети CNN (cellular neural network) шестого порядка. Проанализированы свойства этих последовательностей по их Р-значениям и корреляционной функции. Предлагаемый новый алгоритм для выбора гиперхаотических последовательностей расширенного спектра основан на свойствах гиперхаотических последовательностей. Для доказательства эффективности предложенного алгоритма выбора использованы несколько гиперхаотических последовательностей в системе DS-CDMA. Результаты моделирования показывают, что выбранные гиперхаотические последовательности обладают более высокой эффективностью по сравнению с М-последовательностями и имеют сходные рабочие характеристики с последовательностями Голда. По сравнению с М-последовательностями или последовательностями Голда гиперхаотические последовательности расширенного спектра более пригодны для системы защищенной связи
\end{abstract}

Ключевые слова: гиперхаотическая система; гиперхаотические последовательности расширенного спектра; клеточная нейронная сеть; DS-CDMA; CNN

\section{1. ВСТУПЛЕНИЕ}

Гиперхаос впервые предложен Росслером и определен как система с двумя или большим числом положительных показателей Ляпунова [1]. Вследствие его чувствительности к начальному значению и свойству высокой беспорядочности, гиперхаос находит широкое применение в области связи и обработки изображений. В отличие от обычного хаоса, имеющего только один положительный показатель Ляпунова, гиперхаос характеризуется более слож- ным динамическим поведением, что делает его более привлекательным для систем связи [2]. В результате, все большее число ученых обращают внимание на гиперхаос.

В системе многостанционного доступа с кодовым разделением каналов и прямым расширением спектра DS-CDMA (direct sequence code division multiple access) отдельные пользователи опознаются различными последовательностями расширенного спектра. Поэтому корреляционные свойства этих последовательностей влияют на затухание многолучевой по-

* Работа частично поддержана Национальным фондом поддержки естественных наук Китая в рамках гранта № 61102085 и Инновационным фондом поддержки исследований в области естественных наук при Харбинском технологическим институте в рамках проекта № HIT.NSRIF 201151. 